\title{
Impact of the recession on bioanalysis
}

"... as many contract research organizations seem to have reduced workflow, it would appear that the reduction in business from the small pharmaceutical/biotechnology companies must be more significant..."

It is important to understand that this article is written from the perspective of a scientist rather than an economist. Successful bioanalysis is accomplished through a logical sequence of events prior to arriving at the end point. In order to assess the impact of the current economic situation on bioanalysis, it is necessary to use the same logical thought processes as would be applied to regular bioanalytical problem solving. Therefore, this article attempts to set in context the general economic downturn, the impact of this on pharmaceuticals/biotechnology and the additional complexity of multiple patent expiries, before attempting to summarize the effect of all of this on bioanalysis and bioanalytical outsourcing.

\section{General economic background}

Regarding the general economic outlook at the present time, it is worthwhile to reflect on how we arrived at the current situation and how we are likely to move on from here. There is much debate about the origin of the present financial crisis, there appears to be general agreement, however, that banks and financial institutions lent too much money in the housing market to people with poor credit records. Put another way, people and institutions were encouraged to believe that they could afford to purchase beyond their means - not a recipe for the sustenance of financial stability. Inevitably, when interest rates rose sharply, borrowers began to face repayment difficulties. Unfortunately, only at this point did it become apparent just how much exposure multinational banks had to these bad loans and the result was a previously unimaginable banking crisis, with selected banks either going out of business, having to merge or effectively being nationalized. Due to the global nature of business, the repercussions were felt around the world, though the worst effects were seen in the UK and US financial markets. In the USA and UK, taxpayers are likely to experience the effects of the 'credit crunch' for years to come. At this moment, it is difficult to predict the way forward; banks do not seem to have the confidence to lend to each other, which means that credit - even for stellar customers - is hard to find.

\section{Impact of the recession on pharmaceuticals/biotechnology}

So how did the credit crunch affect the operations of pharmaceutical and biotechnology companies? My observations are based on personal anecdotes and supportive reports from IMS Health [1], Frost and Sullivan [2], Pharmaceutical Times [3], PriceWaterHouseCoopers [4] and Datamonitor [5]. The key impact of the credit crunch on companies in general is the end of access to cheap debt. Datamonitor believes large pharmaceutical companies have stayed away from cheap debt and the pharmaceutical industry is regarded as insulated from the recession to a large extent, because patients will always require medicine. However, new product supply is dependent on rich $\mathrm{R} \& \mathrm{D}$ pipelines. Large companies have traditionally supplemented their own research efforts by in-licensing, some of which involved entrepreneurial startup companies, many of whom do not have the resources to fully fund the escalating costs of drug development independently. These entrepreneurial companies, especially those in the biotechnology sector, have been funded by raising finance from private equity or venture capitalists. In 2007, financing of biotechnology companies reached US $\$ 50$ billion. In the present credit crunch, these funds have evaporated as investors are no longer prepared to back high-risk projects and, thus, many of these companies may not survive. Furthermore, cost cutting in Government healthcare programs is encouraging the growth of the generics market. However, in the long term, the growth of generics will not encourage

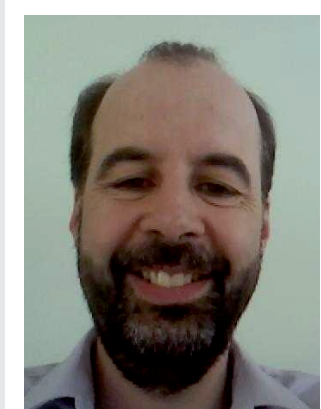

Richard W Abbott Senior Director of Bioanalysis, Department of Biosciences, Shire Pharmaceuticals, Hampshire International Business Park, Basingstoke, Hampshire, RG24 8EP, UK

Tel.: +44 I256894575

Fax: +44 I256894703

E-mail: rabbott@shire.com 
the risk taking necessary to maintain the flow of innovative products essential to meet unmet medical needs. IMS Health [1] predicts that the global pharmaceuticals market will grow by $2.5-3.5 \%$ in 2009 , with global pharmaceutical sales of around US $\$ 750$ billion, down 2\% from a previous forecast in October 2008. IMS see the global financial crisis contributing to this record low sales growth in 2009. One way to encourage growth is to find new markets; the mature pharmaceuticals markets will grow at a rate of $1-4 \%$ over the next 5 years, but the seven emerging markets will grow at a rate of $13-16 \%$, with China moving up from sixth to third in the world pharmaceutical league table. In the future, new product launches are expected to be largely specialist driven, aimed at niche indications with the demise of the blockbuster model.

\section{Impact of patent expiries on pharmaceutical companies}

One of the other issues to affect pharmaceutical companies adversely is the impending succession of patent expiries. While not connected to the current financial crisis, it is worth mentioning as many companies are facing patent expiries between now and 2012, with multiple prescription products about to fall off the 'patent cliff'. Datamonitor forecasts that the top 50 pharmaceutical companies will face patent expiries valued at US $\$ 115$ billion [5]. This is compounded by a dearth in new product registrations and, therefore, companies are struggling to replenish their $\mathrm{R} \& \mathrm{D}$ pipelines. Consequently, many companies are restructuring and reducing headcount, a trend that looks set to continue. Datamonitor also reports that investors are very interested in cash-rich companies such as pharmaceuticals. Consequently, as the price of potential acquisition targets has fallen in the recession, merger and acquisition activity may increase as has been seen recently. Several research-based pharmaceutical companies have diversified by moving into the generics business as it becomes harder to find new blockbuster drugs. According to PriceWaterHouseCoopers, the fully diversified business model is becoming more and more popular [4]. In this model, a company expands from its core pharmaceuticals business into the provision of related products and services such as diagnostics and devices, generics, nutraceuticals and health management. Essentially, the risk in any one segment is spread by moving into several market segments. At the same time, company culture would need to change completely as provision of services would become as important as provision of products.

\section{Impact of recession/patent expiries on bioanalysis}

Having set the scene, how is the impact of the recession, downward price pressure and multiple patent expiries affecting the area of bioanalysis and its outsourcing? Talking with several companies recently, many appear to be less busy than a year ago as lead times are now substantially less, with some CROs offering to start work more or less immediately. However, Contract Pharma reports that the majority of companies have not cancelled outsourced projects due to the economic climate in the past year [6]. As such, the picture seems to be less than clear. There have been some reports of layoffs and salary freezes in CROs, which reinforces the slow nature of business since the start of the year. Why is this happening? Clearly the smaller biotechnology companies that have closed due to the loss of venture capital are no longer outsourcing. On the other hand, there has been an increase in contract bioanalysis from several large pharmaceutical companies who are looking to strategically outsource more work as they reduce their internal capacity. Overall, as many CROs seem to have reduced workflow, it would appear that the reduction in business from the small pharmaceutical/biotechnology companies must be more significant. An additional factor could be an increase in offshoring activity; in terms of outsourcing costs, it would appear that the impact of offshoring to lower cost countries may be starting to make an impact in Western Europe and North America. While issues such as study monitoring, data quality, timelines, compliance and confidentiality still remain concerns for bioanalytical outsourcing managers, it would appear that the magnetic draw of cost reduction is becoming increasingly important for procurement departments. It will be interesting to see how the offshoring trend develops, whether the continued impact will remain when the economic climate improves and whether the regulatory agencies will adopt strategies regarding offshoring activity. It is perhaps significant that an increasing number of both traditional CROs and pharmaceutical companies have built facilities in the emerging markets, both to reduce their costs and to build name recognition in these economies. 
Impact on virtual pharmaceutical companies

A virtual pharmaceutical company is one that inlicenses new products and outsources the associated work, having no laboratory, clinical or manufacturing facilities of their own.

From the perspective of someone working within a virtual pharmaceutical company environment, such as myself, in the short term it may be convenient to initiate bioanalytical work at short notice, taking advantage of the decrease in outsourcing activity. On the other hand, if the trend continues and several service providers go out of business, this would be disastrous, as virtual companies have no internal laboratory alternatives. The outcome would be reduced service provider choice at higher cost and substantially longer lead times, as well as the ongoing issues of product delays, additional multiple method transfers and archive issues.

\section{Bibliography \\ - Websites}

1 IMS Health News Release, April 2009 www.imshealth.com/portal/site/imshealth/ menuitem.a46c6d4df3db4b3d88f611019418c $22 \mathrm{a} /$ ?vgnextoid $=1$ e $61 \mathrm{fa} 8 \mathrm{adbec} 0210 \mathrm{vgnvcm} 10$ 0000 ed $152 \mathrm{ca} 2 \mathrm{rcrd}$

2 Frost and Sullivan Market Insight: what does the global economic downturn mean to the Pharma industry? January 2009 www.frost.com/prod/servlet/market-insighttop.pag? Src $=$ RSS \& docid $=155855105$

\section{Conclusion}

In summary, we are living through interesting times, in which the traditional $R \& D$ model and operating paradigm are being closely questioned. The recession is an important factor in this but it is not the only one, as the simultaneous onset of the patent cliff is also extremely significant. Let us hope that general economic recovery materializes quickly and that the hard strategic questions we have all had to answer will prepare us for future success.

\section{Financial \& competing interests disclosure}

The author has no relevant affiliations or financial involvement with any organization or entity with a financial interest in or financial conflict with the subject matter or materials discussed in the manuscript. This includes employment, consultancies, honoraria, stock ownership or options, expert testimony, grants or patents received or pending, or royalties.

No writing assistance was utilized in the production of this manuscript.
Pharma Times, 29 October 2008 www.pharmatimes.com and www.natap.org/2008/ newsupdates/103108_04.htm

4 Pharma 2020: challenging business models: which path will you take? PriceWaterhouseCoopers, April 2009 www.pwc.com/gx/en/pharma-life-sciences/ pharma-2020-business-models/index.jhtml
5 Datamonitor report: the pharmaceutical industry 2008: current and future trends and strategic issues shaping pharma, March 2008 www.datamonitor.com/store/product/the pharmaceutical_industry_2008_current_and future_trends_and_strategic_issues_shaping_ pharma? productid=DMHC2375

6 Contract Pharma, Annual Outsourcing Survey, May 2009

www.contractpharma.com/articles/ 2009/05/2009-annual-outsourcing-survey 